So far as we know at present, chemotherapeutic action can affect the cell in three ways : by alteration of its surface properties, by direct inhibition of an essential enzyme, or by competitive inhibition of an essential metabolism. The authors' avowed object is to "focus attention on the modes of action of drugs rather than upon the synthesis of ever more variants on their chemical structure", and they may be congratulated upon achieving this object. There are no data in the book on either clinical applications or the experimental side of chemotherapy, and both the medical man and the bacteriologist would probably prefer that the title should be modified to "The Biochemical Basis of Chemotherapy". E. F. G.

\section{$\$ 16$}

\section{THEORETICAL ACOUSTICS}

\section{Vibration and Sound}

By Philip M. Morse. (International Series in Pure and Applied Science.) Second edition. Pp. xix +468. (New York and London: McGraw-Hill Book Co., Inc., 1948.) 33s.

$\mathrm{D}$ . P. M. Ma " of who has made a number of contribut oft to theoretical atomic physics, shows if th fpresent book that the new mathematical techniqus which have been developed for the whyng out of quantum mechanics can be used to andlyse such problems as the behaviour of sound in rooms. A course given by him at the Massachusetts Institute of Technology led to the writing of the book. According to the preface to the first edition, which appeared in 1936, it is intended primarily as a text-book for students of physies and of ccmmunications engineering.

The first aim is to give the student a general introduction to the theory of vibration and sound, and the second to give him a series of examples of the method. of theoretical physics so that he may gain an insight into the way in which a theoretical physicist attacks a problem. Presumably the student of physics whom the author has in mind is one who has approached physics via mathematics, rather than one whose bias is towards experiment. Physies students at universities in Great Britain are not usually expected to devote much time to acoustics, and the intensive mathematical treatment would scarcely be the most effective way of giving them an introduction to the physical principles of recent work in acoustics. Students of mathematical physics will find, however, that they are provided with a systematic exposition of a powerful method of handling many acoustical problems. Research workers in acoustics will be particularly interested in the last chapters, where the theoretical work of Morse and collaborators on absorption and the acoustics of rooms is summarized.

Emphasis is laid on the usefulness of determining the characteristic functions for the normal modes of vibration, the behaviour of a flexible string being examined at some length as the simplest case of a system with an infinite number of allowed frequencies. Vibrations of bars, membranes and plates are then investigated in a similar manner. Analysis of sound waves in air commences with propagation in tubes, in connexion with which the concept of acoustic impedance is first used, followed by a chapter on radiation and scattering, which includes sections on absorption at a surface and transmission through ducts.

The present edition is more than a hundred pages longer than the first one. Some parts have been rewritten; but the main change is the insertion of new material, especially sections dealing with transient phenomena by the technique of the operational calculus. The physical principles underlying the mathematics are well brought out, but there is little attempt to compare the theoretical conclusions with experimental results. Very few references are given, and the reader has to find out for himself in what respects the present treatment differs from that of the classical treatises. For the particular fields which it covers, however, Dr. Morse's book will continue to be of great value.

\section{WORLD FOOD PRODUCTION}

\section{Feeding the Human Family}

Science Plans for the World Larder. By F. Le Gros Clark. (Sigma Introduction to Science, 11.) Pp. ix + 125 + 8 plates. (London: Sigma Books, Ltd., 1947.) 7s. $6 d$. net.

TT would be a tholsand pities if the misleadingly modest titlp of rhis little book, and its inclusion in a series where it is a manifest misfit, were to prevent forhaving the widest possible circulation. It might perhaps more aptly have been called "Cold W for Hot Springs". It is one of those rare books that combines science with humanity, that marries a passion for justice and human rights with a hard logic that faces facts. It is a,s much, if not more, a book for the expert as for the non-scientific inquirer.

Mr. Le Gros Clark's burning conviction that every man, woman and child in the world, without malefit of race, creed or colour, should have access to a diet that can give optimum nutrition is known to all specialists in relevant branches of science in Great Britain, and to many overseas; this conviction is even more intense than that of many of those who attended the Hot Springs Conference and founded the Food and Agriculture Organisation of the United Nations. But his appreciation of the difficulties confronting any attempt to translate into practice the ideals of the former, or even to achieve the much. more limited objectives of the latter, is also greater than that of many other enthusiasts for the full larder as a condition precedent for the full life.

The argument of this short essay is already so concise that it would be folly to attempt further condensation. It covers the ground from consideration of individual, regional and national dietary patterns to world markets; it is concerned as much with the raising of crops and stock as with the transport of processed food from factory to consumer; it recognizes in agriculture an essential industry even more than a way of life. The author, in tackling the contradiction between food surpluses and simultaneous hunger, or indeed famine, has surely made it again abundantly clear that no sincere nutritionist can 'keep out of politics' and yet face the economic issues involved.

Not the least among this book's many virtues is the simple and, generally, attractive and accurate way in which it is written, and not the least among its author's claims to distinction is that the extreme seriousness of his subject never causes him to lose his sense of proportion-or indeed of humour. But perhaps Mr. Le Gros Glark's greatest merit of all is that not only does he see the wood as well as the trees, but that he has also with scrupulous fairness and great technical knowledge examined many of 